\title{
Teenagers science club
}

\section{Antonio Campos Calderón, Cristina Solano}

Antonio Campos Calderón, Cristina Solano, "Teenagers science club," Proc. SPIE 8481, Optics Education and Outreach II, 84810J (15 October 2012); doi: $10.1117 / 12.930074$

SPIE Event: SPIE Optical Engineering + Applications, 2012, San Diego, California, SPIE. United States 


\section{"Teenagers science club"}

Antonio Campos Calderón and Cristina Solano, Outreach Coordination,, Centro de Investigaciones en Óptica, A.C. Loma del Bosque 115, Lomas del Campestre, León, Gto., México, acampos@cio.mx

\section{ABSTRACT}

This is an Initiative project which invites teenagers to work on a research project to learn science in a practical and fun way to motivate them to continue learning science.

\section{INTRODUCTION}

As a response to an invitation of the Science Council of the Guanajuato State (CONCYTEG), it was determined to participate in the first generation of Science Clubs of the Science Academy for children and teenagers (Academia de jóvenes en la ciencia). This program has the objective of approaching the youth to the science world through a research project.

CONCYTEG chooses a group of children, from 10-12 years old, to be prepared for at least two years with monthly visits in a variety of scientific activities which are developed in different institutions and are focused on a variety of fields, such as: physics, chemistry, mathematics, medicine, etc. At the end of this process, it is supposed that the participants enter in high school with an idea about the research work taking place in their State. The most outstanding students are then invited to participate in the second stage of the project: The Science Club.

Our main goal is to release the process to be carried out developing a research project in a friendly way where the teenagers would be able to live the science.

\section{PROJECT'S SESSIONS}

The Science Club project is intended to last at least six four hours sessions. The number of sessions might increase depending on the complexity of the fabrication process of the project selected. The minimum of sessions required for the Science Club program and their general development are listed below.

Optics Education and Outreach II, edited by G. Groot Gregory, Proc. of SPIE Vol. 8481

84810J · @ 2012 SPIE · CCC code: 0277-786/12/\$18 · doi: 10.1117/12.930074

Proc. of SPIE Vol. $848184810 \mathrm{~J}-1$ 
First and second session:

Because the majority of the participants are junior high school students they lack of a broad overview of the optics applications. Therefore, during the first and the second session the students will work on a variety of activities in which they will put into action different optics concepts so as to understand the wide diversity of the daily life applications.

\section{Third session}

Once the teenagers have got familiarized with the optics, another session will be required to define roles. That is, the parts of the project in which each participant will work on and moreover will write a report of activities. The report to be handed in must include: Introduction, theoretical framework, rationale, scope, activities development, results and conclusions. The whole development of the project will be in charge of the teenagers. The tutor will only help and correct details related to the drafting if needed.

Fourth and fifth session:

In these two sessions, the students will be working on scale models of the project or different tests with diverse work environments. All the experimentation required to get the ideal results will be developed under the supervision of the tutor and moreover this process will draw the conclusions.

Though, in first instance the research project is designed for six sessions this may change due to the topic which is chosen by the participants of the club. In this case, the tutor will only verify the project's viability. In case the process of implementation, experimentation or manufacture requires it some extra sessions might be added so as to finish the project.

\section{Last session:}

During the last session the students will integrate their contributions and will present their project to the general public as a manner of demonstrating the development of their activities and in a very didactic way. This may enhance to approach people to get to know the scientific world. Furthermore, people who like or are already interested in science can become familiar with our activities and can get in touch with a place full of experience at developing scientific projects. 


\section{RESULTS}

Science Club "2010-2011"

"Cooking the future" was the name assigned by the six teenagers, fig $1 \mathrm{a}$ and $\mathrm{b}$,that participated for first time in the Science Club, period 2010-2011. After working on a variety of activities concerning to optics such as: photography, light reflection and refraction principles, heat properties and many other themes, the teenagers decided to research and moreover implement a project to raise awareness about the use of solar kitchens, which has been directed to general public.

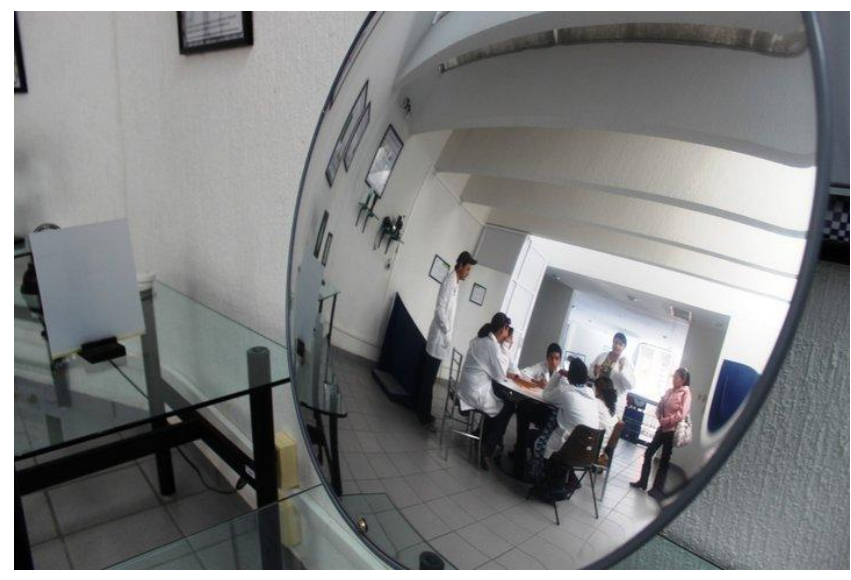

Fig 1a) Science Club participants, 2010-2011

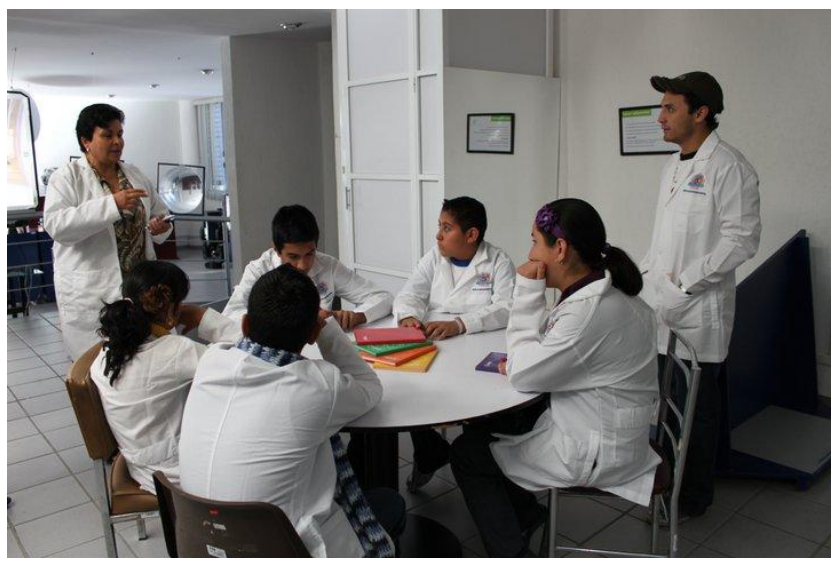

Fig 1 b) Science Club participants, 2010-2011

The teenagers researched the range, materials, forms, and styles of the diversity of solar kitchens. Thus, they created a scale prototype and measured the temperature to test out the effectiveness of the solar kitchens, fig 2 ( $a$ and $b$ ). 


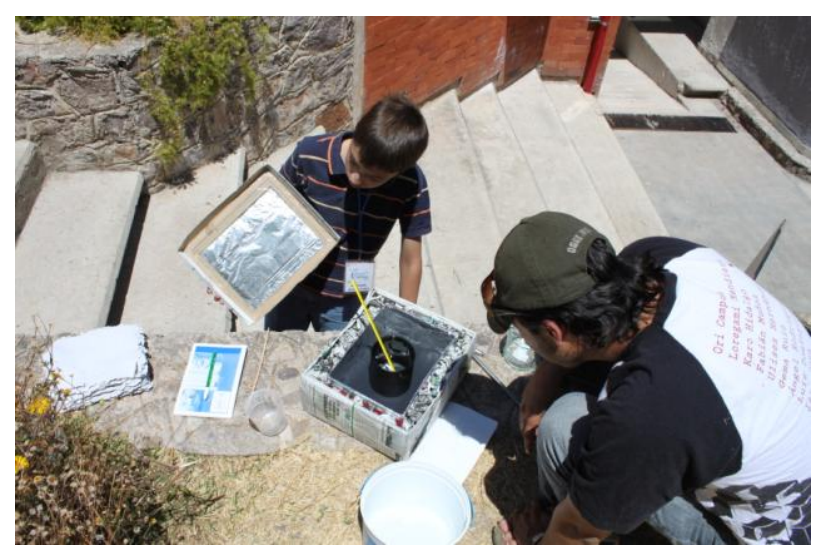

Fig 2a Testing the solar oven

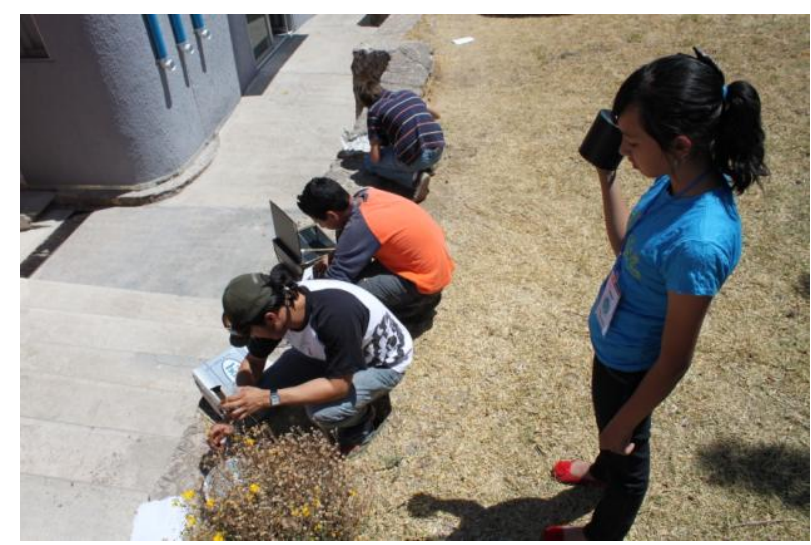

Fig $2 \mathrm{~b}$ Testing the solar oven

Moreover it had been decided to construct two projects: a solar kitchen made out of a satellite dish and a solar oven. Both have been constructed with aluminum frames and acrylic mirrors. The teenagers carried out several tests with different kinds of food such as: roast beef, shrimp broth, cupcakes, spaghetti, cookies and dried fruits.

During the last session the teenagers attended to a water park, where they cooked these type of foods to make a public demonstration about this research project and increase awareness about the use of the solar kitchens. This project participated in the first CONCYTEG Science Club's meeting, where the teenagers won the second price with the project "Cooking the future," fig 3 (a-c). 


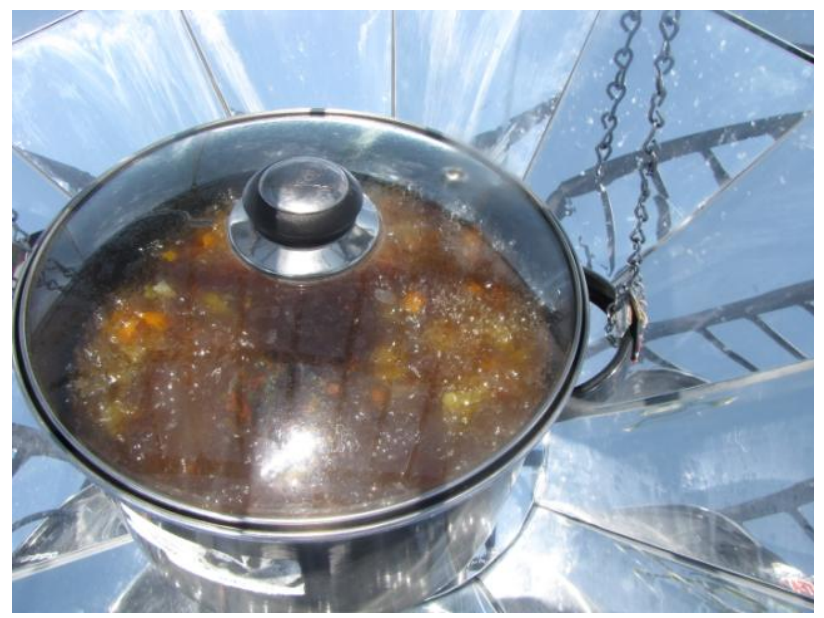

Fig 3 a Solar kitchen and oven demostration

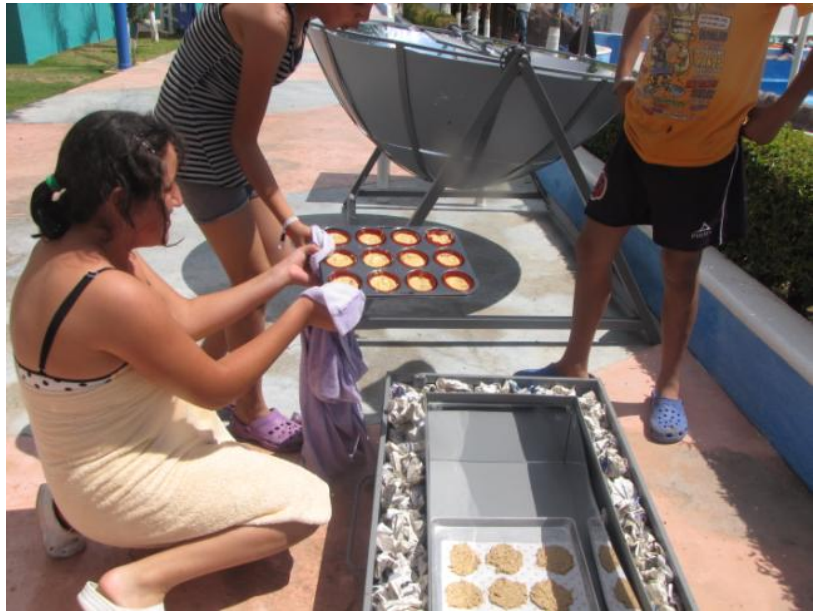

Fig 3 b Solar kitchen and oven demostration

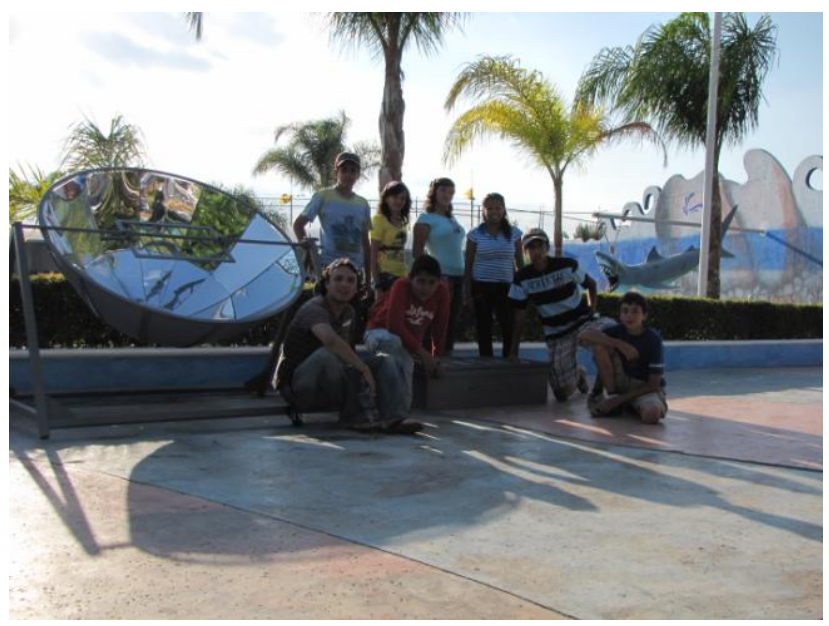

Fig 3 c Solar kitchen and oven demostration

Proc. of SPIE Vol. $848184810 \mathrm{~J}-5$ 


\section{CONCLUSIONS}

At the end of this project the participants discovered a different way of approaching to the science where they realized through a process of research they can find solutions, proposals and improvements to their daily lives, this project is not only useful to the field of optics also any teacher, facilitator or researcher can accomplish in their specialty.

Due to the response obtained with this type of projects and the benefits for the students and general public, the Outreach Coordination of CIO, has the purpose for this 2012 to concrete the creation of a variety of science clubs around the region, especially in marginalized communities. We consider outstanding to give this kind of opportunities to approach the science to everyone. 